\title{
Ciborgue, Comunicação e Sistemas Complexos: uma alternativa à tese da desmaterialização ${ }^{1}$
}

\author{
Fátima Régis ${ }^{2}$ \\ PUCRS
}

\begin{abstract}
Resumo: $O$ tema do ciborgue/pós-humano tem marcado as discussões da cibercultura. $O$ ápice do debate, em geral, desemboca no imaginário de desmaterialização do corpo e da mente e no desejo de transcendência. Nossa hipótese é que a ênfase na desmaterialização deriva de especulações do imaginário sobre a teoria computacional da mente. Segundo esta teoria, não há diferença essencial entre existência corporal e simulação no computador. Com o objetivo de oferecer um contraponto à tese da desmaterialização, o artigo traz para o debate a teoria dos sistemas complexos. Com base no modo de funcionamento dos sistemas complexos, pretende-se encaminhar a seguinte hipótese: a teoria dos sistemas complexos é uma via de pesquisa capaz de sustentar o debate no campo da corporeidade, oferecendo uma alternativa à tese da desmaterialização.
\end{abstract}

Palavras-Chave: Comunicação, sistemas complexos, pós-humanismo.

\footnotetext{
${ }^{1}$ Artigo apresentado no GT "Comunicação e Cibercultura", do XVI Encontro da Compós, na UTP, em Curitiba, PR, em junho de 2007, com o título "A ciência do ciborgue: comunicação, sistemas complexos e cibercultura. O presente texto se beneficiou do debate gerado no GT. Agradeço as sugestões de todos os participantes do GT e, em especial, as leituras cuidadosas e os comentários generosos de André Lemos, Diana Domingues, Eugênio Trivinho e Fernanda Bruno.

2 Fátima Régis é Doutora em Comunicação e Cultura pela Escola de Comunicação (ECO) / UFRJ. É Professora Adjunta da Faculdade de Comunicação Social FCS/UERJ. Atualmente é Coordenadora Adjunta do PPGC da FCS/UERJ. É membro da Associação Brasileira de Pesquisadores em Cibercultura (ABCiber)
} 


\begin{abstract}
The cyborg/posthuman topic has had a continuous presence in the cyberculture discussions. The discussion's summit generally debouches in the Imaginary of body and mind's disembodiment and the transcendence wish. We conjecture that the emphasis in the disembodiment branches from Imaginary's speculation about the computational theory of mind. According to this theory, there is not a substantial difference between physical existence and computational simulation. Aiming to remonstrate the disembodiment thesis, the article brings to the discussion the complex system theory. Founded in the working of the complex systems, the article presents the following hypothesis: the complex system theory is a research channel able to sustain the discussion in the field of embodiment, offering an alternative to the thesis of disembodiment.
\end{abstract}

Keywords: Communication, complex systems, posthumanism.

Résumé: Le theme cyborgue/post-humain devient remarcable dans les discussions sur la culture cyber. Le debat donne sur l'imaginaire de dématérialisation du corps et de la pensée et sur le désir de transcendence. Notre hypothèse est que cette conduction vient des éspeculations de l'imaginaire sur la théorie computationelle de la pensée, selon laquelle il n'y a pas de différence entre l'existance du corps et celle de la simulation de l'ordinateur. Pour refuser cette théorie de la dématérialisation, cet article présente au débat la théorie des systhemes complexes. D'après le comportament des systhemes complexes, notre intention est de soutenir l'hypothèse suivante: la théorie des systhemes complexes est capable de maintenir ce debat sur le domain de la corporeité, lui offrant une alternative à la théorie de la dématérialisation.

Mots-clefs: Communication; systhemes complexes; post-humanisme.

Resumen: El tema del cyborg/post-humano ha marcado las discusiones en los estudios de la cibercultura. El apice del debate, en general, desemboca en el imaginario de la desmaterializión del cuerpo y de la mente y en en deseo de transcendencia. Nuestra hipótesis es la que enfasis en la desmaterialización viene de especulaciones del imaginario sobre la teoría computacional de la mente. Según esta teoría, no hay diferencia esencial entre la existencia del cuerpo y la simulación en la computadora. Con el objetivo de refutar esta tesis, el articulo trae al debate la teoría de los sistemas complejos. Basados en el modo de funcionamiento de estos sistemas, deseamos presentar la seguiente hipótesis: la teoría de los sistemas complejos es una vía de investigación capaz de sustener el debate en el campo de la corporeidad, ofreciendo una alternativa a la tesis de la esmaterialización.

Palabras-Clave: Comunicación; sistemas complejos, post-humano. 


\section{Uma Alternativa à Tese da Desmaterialização}

$\mathrm{Na}$ medida em que as tecnologias da comunicação e da informação evidenciam as hibridações homem-máquina, o tema do ciborgue/pós-humano tornase emblemático das discussões sobre a cibercultura.

O termo ciborgue nasceu com o sonho de aperfeiçoar as capacidades humanas e adaptar o corpo humano para habitar condições inóspitas. Seu inventor, o engenheiro biomédico Manfred Clynes, o definiu assim em 1960: "a mistura do orgânico e do maquínico, ou a engenharia da união entre sistemas orgânicos separados" (GRAY-MENTOR \& FIGUEIROA, 1995, p. 2).

Desde então, e à medida em que se desenvolvem as possibilidades de articulação entre organismos biológicos e maquínicos, têm-se multiplicado as acepções de ciborgue e pós-humano. Este artigo não tem o objetivo de realizar um mapeamento de todas as definições, apenas apresentar as mais relevantes para o prosseguimento do debate aqui proposto.

As definições mais recentes de ciborgue incluem todo tipo de intervenção tecnológica, seja o uso de medicamentos (restauradores da saúde, psicotrópicos ou preventivos contra doenças), seja a conexão com instrumentos de mecânica, eletrônica ou informática. Para Gray, Mentor e Figueroa-Sarriera:

Qualquer pessoa com um órgão, membro ou suplemento artificial (como um marca-passo), qualquer um reprogramado para resistir a doenças (imunizado) ou drogado para pensar/comportar-se/sentirse (psicofarmacologia) melhor é tecnicamente um ciborgue (1995, p. 2).

Um ponto curioso desta definição é que a intervenção não se reduz ao aperfeiçoamento biológico. Ela visa também aprimorar as capacidades psicológicas.

Uma visão mais filosófica e política é a das feministas e dos pesquisadores da teoria crítica, para quem o ciborgue / pós-humano permite superar o ideal de sujeito natural, racional e superior do humanismo moderno (Cf. HARAWAY, 1996; SHILDRICK, 1996, EUBANKS, 1996).

Mas são nas definições de pós-humano que encontramos os desejos de superação mais radicais. O pós-humano é entendido como um passo evolutivo da 
espécie. Nesse caso, o prefixo pós implica a idéia, não apenas de um estágio posterior, como também ontologicamente mais avançado da espécie.

De acordo com os pensadores transhumanistas, pós-humano é "um ser hipotético do futuro cujas capacidades básicas superaram tão radicalmente às dos humanos atuais a ponto de não serem mais inequivocadamente humanos segundo nossos padrões correntes" 3

Uma outra acepção do termo defende que:

Pós-humanos seriam uma simbiose de humanos e inteligência artificial, ou consciências carregadas no computador, ou o resultado de pequenos, mas profundos aprimoramentos tecnológicos em um humano biológico, i.e. um ciborgue 4 .

O que se destaca nessas definições é o desejo de superação dos limites do humano, tendo como ápice o upload da consciência no computador. O sonho (ou pesadelo, dependendo do ponto de vista) do upload da mente tornou-se popular com o já clássico livro Neuromancer, de William Gibson e ganhou contornos científicos com a obra de divulgação científica de Hans Paul Moravec Mind Children, na qual o cientista descreve como seria o processo de transmigração da mente para o computador (Cf. 1988, p. 109).

O upload da mente baseia-se em uma concepção bem aceita nos meios científicos e filosóficos: a tese de que "tudo são sistemas que processam informação" (Cf. DENNETT, 1996, HAYLES, 1999). Ou seja, a idéia de que, como a informação perpassa diversas áreas do conhecimento e é subjacente à constituição da matéria $\mathrm{e}$ da energia, ela seria uma pedra de roseta capaz de transitar sem obstáculos pelos campos orgânico e inorgânico, natural e artificial.

O que freqüentemente passa despercebido pelas análises sobre o póshumanismo é que a noção de que tudo são sistemas que processam informação não equivale à idéia de passagem para dados implicada pelo upload da mente. O fato é

3 Cf. http://www.wikipedia.org, acesso em 25/08/2007. Tradução livre para: "A posthuman or post-human is a hypothetical future being whose basic capacities so radically exceed those of present humans as to be no longer unambiguously human by our current standards".

4 Cf. http://www.wikipedia.org, acesso em 25/08/2007. Tradução livre para: Tradução livre para "Posthumans could be a symbiosis of human and artificial intelligence, or uploaded consciousnesses, or the result of making many smaller but cumulatively profound technological augmentations to a biological human, i.e. a cyborg. 
que existem vertentes científicas que investigam a premissa de que tudo são sistemas que processam informação, sem no entanto, reduzi-la a um processo de desmaterialização.

Este artigo apresenta a hipótese de que a tese da desmaterialização do corpo e da mente é fortemente influenciada por especulações do imaginário tecnológico sobre a teoria computacional da mente que defende que não há diferença essencial ou demarcações absolutas entre existência corporal e simulação no computador.

A teoria computacional da mente é defendida por cientistas como Hans Paul Moravec e Marvin Minsky, ambos do Massachusetts Institute of Technology MIT. Eles definem processos mentais como a manipulação de representações simbólicas de acordo com regras da lógica formal. Por esta visão, a simulação de computador é capaz de modelar inteiramente a vida mental humana. A correspondência entre cérebro e computador baseia-se na concepção funcionalista da mente: a idéia de que emoções e sentimentos como dor, medo e ciúmes não se definem como experiências sensíveis ou eventos físicos no cérebro, mas por seu papel funcional abstrato. Se a atividade cognitiva depende principalmente de meios formais e representacionais, a ação concreta sobre o mundo não é fundamental para o pensamento. Esses pesquisadores alegam que máquinas são capazes de experimentar estados mentais cognitivos genuínos e que é possível construir um computador com emoções e consciência reais.

Essas idéias, combinadas com o conceito clássico de informação como padrão e não como presença (Shannon \& Weaver), parecem autorizar a tese de que tudo que existe pode ser passado para dados, culminando no processo de desmaterialização do corpo e da mente e,_tornando-se as fontes de inspiração para o imaginário cibercultural do desejo de transcendência e unidade com a máquina.

Sem desmerecer a teoria computacional da mente, este artigo propõe trazer para o debate a teoria dos sistemas complexos. A rentabilidade desta teoria para a análise da questão é que ela não prescinde do mundo físico. Pensadores da complexidade explicam a mente como o resultado de um longo processo evolutivo que envolve as relações entre corpo e cérebro e suas interações com o ambiente. Para 
eles, a mente é corporificada e depende da história biológica e cultural vivenciada em situações concretas pelos seres.

Com base na explicação sobre o modo de funcionamento dos sistemas complexos, o artigo pretende encaminhar a seguinte hipótese: a teoria dos sistemas complexos é uma via de pesquisa capaz de sustentar o debate no campo da corporeidade, oferecendo uma alternativa à tese da desmaterialização.

Vamos começar descrevendo como o advento do computador permitiu investigar um tipo de sistema até então intocado pela ciência, os sistemas complexos.

\section{O Que São Sistemas Complexos?}

Um sistema é um conjunto de elementos que estão em interação entre si formando um todo único. Podemos dividir os sistemas em duas grandes categorias: simples e complexos.

Sistemas simples são aqueles que têm apenas duas ou três variáveis, como o movimento dos corpos na mecânica clássica. Sistemas deste tipo são tratados desde a ciência clássica por procedimentos de análise. A análise, legado do método cartesiano, prevê a separação do todo em frações até que se atinja as partes mais elementares. Isoladas as partes elementares, identificam-se os poucos atributos desses elementos e, a partir desses dados básicos, reconstituem-se as características do sistema como um todo ( $C f$. OLIVEIRA, 2003, p. 140-141). Pelos procedimentos de análise, considera-se que não há interação entre as partes ou que esta é tão fraca que pode ser desprezada para fins de pesquisa. Sem a interação entre as partes elementares, nos sistemas simples, o todo é uma soma das partes e mantém as mesmas propriedades destas. Sistemas simples são deterministas - conhecendo-se a situação do sistema num dado momento pode-se calcular seus estados anteriores e prever os subseqüentes - e reducionistas - porque as propriedades do todo são reduzidas às propriedades das partes simples.

Já os sistemas complexos são dinâmicos e não-lineares. São sistemas em que o conjunto das variáveis não obedece a uma relação constante de proporcionalidade, mas isto não significa desordem. São sistemas sensíveis às condições iniciais, isto é, de acordo com as variações que ocorram no estado inicial do sistema, sua evolução se 
torna imprevisível. São por essa razão sistemas de comportamento caótico, pois mudam de estado sob efeito da ação do tempo. Sistemas que podem alterar seu estado de acordo com sensíveis variações nas condições iniciais e com a ação do tempo podem ser ilustrados pela metáfora já famosa do "efeito borboleta". Este efeito foi analisado pela primeira vez pelo matemático Edward Lorenz na década de 1960. Lorenz estudava efeitos climáticos e percebeu que ínfimas mudanças nas variáveis iniciais dos sistemas meteorológicos amplificadas pela ação do tempo poderiam causar alterações drásticas no final do sistema. Explicou sua tese com a analogia de que o simples bater de asas de uma borboleta no Brasil poderia causar um tornado no Texas5. A metáfora revela duas características importantes dos sistemas complexos: a extrema sensibilidade a ínfimas alterações no estado inicial do sistema e a interdependência entre suas variáveis. Um sistema deste tipo descreve uma situação em que o comportamento do conjunto excede a soma de cada uma de suas partes. O procedimento de análise não é eficaz quando aplicado a sistemas não-lineares.

Existem sistemas de complexidade organizada e de complexidade desorganizada $^{6}$. Este texto se interessa pelos sistemas que exibem uma complexidade organizada. Sistemas organizados precisam ser investigados como um todo, porque seu comportamento é produzido pela interação entre as partes constituintes. Seu comportamento não é propriedade dos elementos da matéria, ele emerge da interação entre os componentes da matéria. As características ou comportamentos que surgem não são redutíveis às propriedades ou comportamentos das partes elementares.

\footnotetext{
5 A inspiração parece ter origem no conto de ficção científica "A Sound of Thunder" (Um Som de Trovão), escrito em 1952, por Ray Bradbury.

${ }^{6}$ Os sistemas de complexidade desorganizada caracterizam-se por terem milhões ou bilhões de variáveis. Nesses sistemas não é possível fazer prognósticos sobre o comportamento de um elemento isolado, mas pode-se fazer previsões exatas sobre o comportamento global do sistema. O movimento randômico executado pelas moléculas de um gás à medida que colidem umas com as outras é um exemplo. Dado seu comportamento caótico é impossível conhecer detalhadamente os estados microscópicos e prever a partir das leis do movimento como uma molécula individualmente irá se comportar. Este tipo de sistema só começou a ser estudado a partir do século XIX com a criação dos métodos estatísticos e probabilísticos. Steven Johnson explica que este tipo de sistema é complexo "porque há muitos agentes se inter-relacionando, mas é desorganizado porque eles não criam qualquer comportamento de nível superior, além de amplas tendências estatísticas" (2003, p. 35) Além dos gases, outros exemplos são os sistemas de seguros e a previdência.
} 
Diferente dos sistemas simples em que praticamente não há interação entre os agentes elementares, nos sistemas de complexidade organizada a efervescência de interações entre as partes elementares é o cerne do sistema. Essas partes simples interagem entre si por meio de regras específicas e locais (não programadas por um agente de nível superior) criando um comportamento observável no nível macro ou, com o passar do tempo, gerando um padrão específico ordenado, ou seja, produzem o fenômeno da auto-organização.

Para entendermos melhor o que é e como funciona o fenômeno da autoorganização, tomemos um exemplo prático: a emergência de padrões em ambientes urbanos. Em 1842, Friedrich Engels chegou à cidade de Manchester para supervisionar a fábrica de algodão pertencente a sua família. Engels, que já era amigo de Marx, usou os três anos que passou em Manchester, patrocinado por sua família burguesa, realizando as pesquisas que deram origem a um dos tratados sobre urbanismo no século XIX, A condição da classe operária na Inglaterra. Manchester é reconhecidamente uma cidade que foi construída sem nenhum tipo de planejamento. Mas, no meio do crescimento desordenado, Engels identificou um estranho padrão:

A própria cidade é construída de uma maneira peculiar, de modo que uma pessoa pode morar nela durante anos, entrar e sair dela diariamente sem ter contato com um bairro popular e nem mesmo com operários - quer dizer, contanto que a pessoa se limite aos seus próprios negócios ou a passear por puro prazer. Isto decorre principalmente das circunstâncias de que, através de um acordo tácito e inconsciente, assim como de uma intenção explícita e consciente, mantêm os bairros populares totalmente separados das partes da cidade reservadas à classe média...

Sei muito bem que essa maneira enganosa de construir é mais ou menos comum a todas as grandes cidades. Sei também que, em virtude de seu tipo de negócio, os comerciantes precisam alojar-se nas vias principais, de muito movimento. Sei que nessas ruas, há mais casas boas do que casas humildes, e que o valor do terreno é mais alto nas redondezas do que nos locais mais afastados. Mas, ao mesmo tempo, em nenhum outro lugar, a não ser em Manchester, vi um isolamento tão sistemático das classes operárias. Nunca vi em outro lugar ocultar-se com tão fina sensibilidade tudo que pudesse ofender os olhos e os nervos da classe média. E, no entanto, mais do que acontece com qualquer outra cidade, Manchester, foi construída com menos planejamento e menos restrições por parte de regulamentos oficiais do que qualquer outra cidade - na verdade, cresceu ao acaso. Ainda assim... não consigo deixar de sentir que os industrialistas liberais, os 'bigwigs' de Manchester, não são 
inocentes desse estilo acanhado de construção. (ENGELS apud JOHNSON, 2003, p. 26-27)

Como Johnson destaca, o que Engels distinguiu no cenário urbano foram padrões visíveis porque têm uma estrutura repetitiva que os distingue do mero ruído de fundo: "são sinais emergindo de um lugar do qual só esperaríamos ruídos" (JOHNSON, 2003, p. 29).

Essas estruturas emergentes não são criadas por leis governamentais ou projetos urbanos, mas por milhões de indivíduos e algumas regras simples de interação social. Tradicionalmente, os indivíduos se aproximam de seus pares e mantêm distância tácita com os diferentes, os 'outros'. Essas regras simples de 'convívio social' 'empurram' as classes desfavorecidas para os lugares mais escondidos da cidade.

Como podemos deduzir, nem todo sistema emergente é desejável. Nos padrões emergentes observáveis no plano macro das cidades incluem-se, por exemplo, as favelas. No plano social o fenômeno da auto-organização pode significar um processo de segregação social.

A auto-organização envolve a emergência (e manutenção) da ordem, ou complexidade, a partir de uma origem ordenada em um nível inferior. Não significa apenas mudanças superficiais, mas implica um desenvolvimento fundamental da estrutura. Este desenvolvimento é 'espontâneo' ou 'autônomo' obedecendo a características intrínsecas ao próprio sistema, que freqüentemente está interagindo com o meio ambiente, em vez de ser imposto ao sistema por um programador externo ( $C f$. BODEN, 1996, p. 3). O modelo da auto-organização é um modelo de um mundo sem líderes, em que o comportamento observável em plano macro emerge a partir de interações entre os elementos simples nos níveis inferiores. Os protestos contra a Organização Mundial do Comércio em Seatlle, em 1999, o clima, a vida, a sociedade, as colônias de formigas e o mercado financeiro são sistemas desse tipo. Algumas áreas da cibercultura, tais como redes de auto-organização, mídias táticas, sistemas de compartilhamento de informações e softwares emergentes funcionam segundo princípios de auto-organização.

Mas ser auto-organizável ainda não é tudo. A tecnologia da Web pode ser brilhante para conectar (fazer circular informações), mas ainda é pobre em gerar 
ordem de nível superior. A web pode ser auto-organizável, mas não é adaptável. (JOHNSON, 2003, p. 87)

Para criar um padrão de nível superior, o sistema precisa ser adaptável. Ou seja, reagir às necessidades específicas e mutantes de seu meio ambiente, incrementando assim o potencial de ficar mais inteligente com o tempo. Steven Johnson (2003, p. 86) salienta que inteligência requer conexão (interação) e organização.

O elemento que os sistemas emergentes adaptáveis utilizam para se ajustar às necessidades do meio é um velho conhecido dos estudiosos de comunicação, o feedback. Ele está presente em todo lugar. As formigas o utilizam para definir se precisam buscar alimentos ou trabalhar na limpeza da colônia. As células do corpo humano o utilizam para decidir se serão células da pele ou neurônios. Os comerciantes para ordenar a logística de entrada e saída de produtos. Os profissionais de comunicação, para ajustar o tipo de mensagem para seu público. Os autores de novela o utilizam para decidir o rumo de personagens e histórias. $\mathrm{O}$ feedback é uma ferramenta que permite ajustar o sistema para que ele se torne adaptável. (JOHNSON, 2003, p. 103)

Os termos informação, interação, troca, vizinhança, feedback indicam uma outra característica muito curiosa dos sistemas complexos: eles exibem um comportamento comunicacional.

O ponto de interseção entre as manifestações contra a globalização em Seattle, a efervescência da cidade de Manchester, o comportamento das formigas e o software Simcity, é que todos são sistemas de auto-organização. Todos partem de agentes simples que interagem entre si segundo regras locais (bottom-up), ouvindo o feedback das células vizinhas e, produzindo como resultado um padrão reconhecível (adaptável ou não) a nível macro.

Seja por meio de sinais semioquímicos como os feromônios usados nas interações entre formigas, ou todo tipo de códigos lingüísticos complexos (gestuais, verbais, arquitetônicos, vestuário etc) usados pelos humanos em suas comunicações diárias, é o processo de troca de informação que permite as aproximações ou 
afastamentos entre as partes elementares de um sistema, gerando padrões de comportamento observáveis no nível macro.

A base dos sistemas complexos é o reconhecimento de padrões. Reconhecer padrões é criar uma sinalização, é gerar uma diferença. Um sinal é um padrão que se destaca do ruído; é uma figura que se destaca de um fundo. A informação é um padrão que se destaca de um fundo. Reconhecer um padrão é codificar um sinal capaz de ser compreendido por outro ser. As reações que o sinal causa no meio irão provocar os feedbacks, que, por sua vez, reorientarão os passos futuros do sistema.

\section{Sintetizar: o novo procedimento científico}

Antes da invenção do computador, os cientistas conseguiam investigar os sistemas simples e os sistemas de complexidade desorganizada. Os primeiros eram tratados por equações analíticas e os últimos por métodos estatísticos e probabilísticos. O computador permitiu o estudo dos sistemas de auto-organização, expandindo imensamente as possibilidades de investigação científica.

Vamos tentar compreender como isso ocorre. A meteorologia conhece os componentes e as equações atmosféricas, mas para prever o tempo, precisa calcular as "implicações das interações de um vasto número de variáveis partindo de complicadas condições iniciais" (SIMON, 1999, p. 15). Na ausência do computador, os pesquisadores precisavam utilizar cálculos integrados de modo que as equações fossem integradas sucessivamente, simulando o desdobramento do comportamento do sistema com a passagem do tempo. Sem o computador, a tarefa era praticamente inexeqüível. Para desvendar os mistérios desse tipo de sistema é preciso modelar o comportamento do sistema quase que em tempo real, o que só se tornou possível com o desenvolvimento das simulações de computador.

Para produzir simulações, o computador utiliza procedimentos de síntese. Diferente do método analítico - que decompõe o todo em suas partes constituintes -, a síntese inicia com as partes constituintes, colocando-as juntas na tentativa de sintetizar o comportamento de interesse.

A partir de descrições pormenorizadas de componentes e leis de comportamento, o computador calcula a evolução dos sistemas a partir de uma 
ampla faixa de parâmetros e condições iniciais, permitindo criar praticamente todos os fenômenos possíveis, existentes ou não. Por exemplo, os simuladores de vôo mais modernos modelam não apenas todo tipo de situação que o piloto enfrentará na realidade, mas também condições climáticas extremamente improváveis como nevar no Rio de Janeiro ( $C f$. KENSKI, 2001, p. 67).

A miríade de sistemas que podem ser simulados transformou o computador em uma ferramenta presente praticamente em todos os campos de pesquisa. É possível sintetizar situações variadas tais como condições climáticas nos quatro cantos da Terra, comportamento de colônias de insetos e fluxos populacionais de grandes cidades. Mas por que esses milagres operados pelas novas técnicas computacionais nos interessam? Porque eles revelam um ponto de divergência importante entre a teoria computacional da mente e os sistemas complexos.

Resumidamente, a teoria computacional da mente opera com as modelizações da mente produzidas pelas simulações de computador por meio dos processos de síntese.

Já os teóricos da complexidade fizeram uma descoberta notável com os processos de síntese: o uso da simulação para investigar sistemas complexos ensinou que "comportamento complexo não precisa de raízes complexas" (LANGTON, 1995, p. ix). Perceberam que suas pesquisas não precisavam se limitar a simular os sistemas existentes: poderiam colocar juntas substâncias e partes da matéria que não aparecem juntas na natureza e ver que outros sistemas poderiam emergir dessas interações.

Sintetizar é mais do que reproduzir processos naturais, é criar objetos e substâncias que não existem na natureza.

\section{Complexidade: como criar um ciborgue/pós-humano}

A síntese ensinou a projetar outras possibilidades da natureza; criar "realidades alternativas", como as descrevem os escritores de ficção científica. Simular ou criar modelos não é um procedimento novo. A originalidade também não está em fabricar artefatos e instrumentos que não existem na natureza. A novidade consiste na possibilidade de intervir sobre os mecanismos da vida, um processo que, 
até então, era lento e exclusivo da seleção natural. O que nos remete à problemática do ciborgue/pós-humano.

Como explica Luiz Alberto Oliveira, do ponto de vista dos sistemas complexos:

a vida é uma matéria organizada que, aprendendo a modificar sua própria estrutura para responder a alterações do meio, passou a conectar as durações bilionesimais das reações moleculares aos milhares de anos das transformações geológicas, às centenas de milhões das transformações astrofísicas. A aceleração técnica vigente na contemporaneidade superpôs a essa conexão entre os ritmos materiais e biológicos o prestissimo das produções culturais. (2003, p. 167)

Enquanto a seleção natural leva bilhões de anos para talhar uma nova espécie de Bionte - ser vivo desenhado pela seleção natural -, o homem precisou de apenas algumas décadas para gerar seu primeiro mamífero Bióide - ser vivo projetado artificialmente: a ovelha Dolly.

Ora, se nos níveis elementares os seres vivos são constituídos das mesmas substâncias que a matéria inerte ${ }^{7}$ e, o método científico da complexidade é a síntese que implica em reunir elementos simples e fazê-los interagir a fim de que se gere

\footnotetext{
7 A temática ciborgue/pós-humano é inaugurada quando, em meados do século XX, a biologia inspira-se nos estudos da cibernética e passa a descrever o ser vivo como o resultado de uma organização que se ordena a partir da idéia de arquitetura em níveis. Ou seja, os componentes de um nível inferior interagem e integram-se entre si, ao mesmo tempo em que se integram no nível superior. Essa lógica fundamenta-se em dois pontos cruciais para $o$ surgimento da noção de ciborgue/pós-humano. O primeiro se refere ao fato de que, nos níveis inferiores a vida é composta de elementos inorgânicos, de onde surge a conclusão de que nos níveis elementares da matéria não há diferença entre organismos biológicos e matéria inerte. Por meio de reações enzimáticas as substâncias inorgânicas tornam-se moléculas específicas que, por sua vez, constituem células que formam órgãos e assim por diante. Ao final de várias etapas de integrações sucessivas em níveis, temos um ser vivo completo. O que orienta essas integrações sucessivas é um conjunto de informações organizadas em um programa, cifrado nos códigos do DNA. Chegamos ao segundo ponto crucial: descrito à luz da cibernética, o ser vivo passa a ser um sistema que processa informações e executa programas. Órgãos, células e moléculas trocam mensagens sob forma de interações bioquímicas, formando uma rede de comunicação.

Desde então, os conceitos de informação, código e programa têm gerado uma convergência de materiais e métodos entre as ciências da vida, a microeletrônica e as tecnologias informacionais da comunicação ( $C f$. CASTELLS, 2001). A informação tem se ramificado por áreas diversas como biologia, ciências cognitivas e comunicação, e atuado como um solvente universal ( $C f$. HAYLES, 1999), capaz de articular sem emendas organismos biológicos e dispositivos inorgânicos. O resultado é o surgimento das noções de ciborgue e pós-humano: o hibridismo entre componentes biológicos e cibernéticos com objetivo de superar os limites do humano.
} 
comportamento complexo -, não há rigorosamente nada que impeça de sintetizar carbono e silício. Do ponto de vista científico, não há nada que impeça de se combinar os componentes orgânicos - com suas habilidades motoras, sensórias e cognitivas - de que somos constituídos com as próteses e chips sensíveis, inteligentes e biocompatíveis das tecnologias artificiais - e ver o que acontece. À medida em que a ciência amplia a capacidade de manipular partículas em escala molecular, aumenta a possibilidade de criar os Borgs - seres híbridos de células e chips. (Cf. OLIVEIRA, 2003, p. 169)

Para enfatizar o argumento, Oliveira lembra uma façanha:

O cérebro de uma lampreia foi conectado a sensores sensíveis à luz e também aos controles de movimento de um pequeno robô. Com o cérebro da lampreia funcionando como central de processamento, o robô passou a agir como a lampreia agiria, evitando as zonas iluminadas e buscando as escuras (OLIVEIRA, 2003, p. 169).

Pensar o tema do ciborgue/pós-humano via sistemas complexos traz uma alternativa à tese da desmaterialização. Pela teoria dos sistemas complexos, a noção de que "tudo são sistemas que processam informação" ganha um novo matiz. Não é uma redução de toda a complexidade do humano a um padrão de dados capaz de fluir por um circuito cibernético. Trata-se de uma inspiração na própria lógica da vida: agentes elementares que trocam informações seguindo regras locais de interações, de onde podem emergir seres com comportamento adaptativo e inteligente. Esse modo de análise pode fornecer ao debate uma base científica, ampliando o campo de investigação sobre o tema.

Em segundo lugar, algumas áreas da cibercultura, tais como redes de autoorganização, mídias táticas, sistemas de compartilhamento de informações e softwares emergentes, já utilizam procedimentos de síntese para gerar autoorganização. Auto-organização e emergência são características dos sistemas complexos que, como nos parece, fundamentam-se nos modelos de comunicação. 


\section{Referências Bibliográficas:}

BELL, David \& KENNDY, Bárbara M. (orgs). The Cibercultures Reader. London: Routledge, 2002.

BODEN, M. A. (ed.). The philosophy of artificial life. New York: Oxford University Press, 1996.

BRADBURY, R. “Um Som de Trovão”. In: Os frutos dourados do sol. São Paulo: Editora Círculo do Livro, 1979.

CASTELLS, M. A sociedade em rede. Rio de Janeiro: Paz e Terra, 2001.

DENNETT, Daniel. Kinds of Minds. New York: Basic Books, 1996.

EUBANKS, Virginia. "Zones of Dither: Writing the Postmodern Body". In: Body and Society, vol. 2, n 3. Londres: Sage Publications, 1996.

FELINTO, E. A religião das máquinas. Porto Alegre: Sulina, 2005.

GRAY, Chris H; MENTOR, Steven; FIGUEIROA-SARRIERA, Heidi. "Cyborgology: constructing the knowledge of cybernetic organisms". In: The cyborg Handbook.. Nova York e Londres: Routledge, 1995.

HAYLES, K. How we became posthuman. Chicago University, 1999.

JOHNSON, S. Emergência: a dinâmica de redes em formigas, cérebros, cidades e softwares. Rio de Janeiro: Jorge Zahar Editor, 2003.

LANGTON, C. "Introduction”. In: LANGTON, C (ed.) Artificial life. The MIT Press, 1995.

LEMOS, A. Cibercultura. Porto Alegre: Sulina, 2002.

MITCHELL, William. Me ++: The Cyborg Self and The Network City. Cambridge: MIT Press, 2003.

MORAVEC, H P. Mind children. Cambridge: Harvard University Press, 1988.

OLIVEIRA, L A. "Biontes, bióides e borgues". In: NOVAES, A (org.). O homemmáquina: a ciência manipula o corpo. Rio de Janeiro: Companhia das Letras, 2003.

PINKER, Steven. Como a mente funciona. São Paulo: Companhia das Letras, 1998.

RÉGIS, Fátima. Nós,ciborgues: a ficção científica como narrativa da subjetividade homem-máquina. Rio de Janeiro: ECO / UFRJ, 2002. (Tese de Doutorado)

SANTAELLA, L. Comunicação e Pesquisa. São Paulo: Hacker Editores, 2001. . Culturas e artes do pós-humano: da cultura das mídias à cibercultura. São Paulo: Paulus, 2003.

SEARLE, J. Mente, Cérebro e Ciência. Lisboa: Edições 70, 1987.

SHANNON, C \& WEAVER, W. Teoria Matemática da Comunicação. Rio de Janeiro: Difel, 1975.

SHILDRICK, Margrit. "Posthumanism and the monstrous body". In: Body and Society, vol. 2, n 1. Londres: Sage Publications, 1996. 
SIMON, H. A. The sciences of the artificial. 3 ed. The MIT Press, 1999.

\section{Periódico:}

KENSKI, R. A arte de voar sem sair do chão. Superinteressante, São Paulo, jun de 2001. 